\title{
Effects of an FSS Reflector on a Microstrip Line Fed Bow-Tie Slot Antenna
}

\author{
Augusto César Rebouças de Brito ${ }^{1}$ (D), Antonio Salvio de Abreu ${ }^{1} \mathbb{C}^{\circ}$, Adaildo Gomes D’Assunção ${ }^{1}$ (D), \\ Custódio Peixeiro ${ }^{2}$ \\ ${ }^{1}$ Federal University of Rio Grande do Norte, Department of Communication Engineering, Caixa Postal 1655, \\ CEP: 59078-970, Natal,RN, Brazil,augustocrb@hotmail.com,asabreu@ct.ufrn.br,adaildo@ct.ufrn.br \\ ${ }^{2}$ Instituto de Telecomunicações, Instituto Superior Técnico, University of Lisbon, Av. Rovisco Pais, 1, 1049-001 \\ Lisbon, Portugal, custodio.peixeiro@lx.it.pt
}

\begin{abstract}
This paper describes the analysis of the effects of a frequency selective surface (FSS) on the characteristics of a microstrip line fed antenna with a bow-tie slot in the ground plane for operation in the frequency range 1 to $10 \mathrm{GHz}$. The use of the FSS is proposed to miniaturize the antenna structure and increase the number of resonance frequencies and the gain. Air gaps can be inserted between the antenna and the FSS to allow for the adjustment of the resonance frequencies and increase the bandwidth. To prove the concept, antenna prototypes printed on a $30 \times 30 \mathrm{~mm}^{2}$ FR4 low-cost substrate are designed, fabricated and tested. Good agreement is obtained between numerical simulations and experimental results, thus validating the proposed design procedure. The obtained miniaturization and multiband effects can be most convenient for multiservice wireless system applications such as WLAN, WiMAX, 4G, and 5G mobile communication systems.
\end{abstract}

Index Terms - Frequency-selective surface, FSS, Microstrip antennas, Mobile communication systems, Planar antennas, Slot antennas.

\section{INTRODUCTION}

The development of wireless systems and the generalization of their employment in recent years have made the use of compact multiband and broadband antennas a major attraction, particularly important for commercial and military applications. The most common examples are encountered in a variety of portable wireless communication devices such as cell phones, handsets, palmtops, and laptops. The emergence of different wireless technologies such as global system for mobile communications (GSM), radio frequency identification (RFID), Bluetooth, Wi-Fi, Worldwide Interoperability for Microwave Access (WiMAX), and lately 4G, 5G and the Internet of Things (IoT), has served as motivation to boost research seeking lighter, more compact, and more cost effective devices, using planar microstrip antennas. The design of antennas with these characteristics, possibly without loss of performance, is still a challenge for researchers [1]-[3]. 
Journal of Microwaves, Optoelectronics and Electromagnetic Applications, Vol. 19, No. 3, September 2020 DOI: http://dx.doi.org/10.1590/2179-10742020v19i38

Ground-plane slot microstrip antennas are known for their advantages, such as large bandwidth, good impedance matching and the ability to fully integrate active or passive components [4]. Moreover, the combination of antennas with FSS structures can enhance certain antenna characteristics. Combination of many different type of microstrip antennas and FSSs have been proposed in the literature [5]-[9]. In [5] a FSS is used to increase the broadside gain of a patch antenna almost $7 \mathrm{~dB}$, at the X band. In [6] a FSS superstrate layer is used to increase both the impedance bandwidth and the gain of an aperture coupled microstrip patch antenna. An EBG structure is proposed in [7] to reduce mutual coupling between meanderline MIMO antennas. In [8] a conformal metamaterial lens-based radome is used to suppress surface waves which resulted in gain enhancement and reduction of side-lobes. A compact FSS multilayer structure composed of reactive impedance surfaces is used in [9] to convert linear into circular polarization.

This paper proposes the combination of a microstrip line fed bow-tie slot in the ground plane antenna with an FSS superstrate to miniaturize the structure and increase the number of resonance frequencies and the gain. Moreover, the use of an FR4 substrate promotes a low cost solution. The insertion of an air layer between the antenna and the FSS structure introduces an additional degree of freedom that provides fine adjustment of the resonance frequencies. Such characteristics are very attractive for application in the new multi-standard terminals of $4 \mathrm{G}$ and $5 \mathrm{G}$ wireless mobile communication systems.

The paper is divided into 7 sections. After this section I, the introduction, section II deals with a rectangular slot that is analyzed to serve as reference for the bow-tie slot antenna described in section III. The analysis and design of the proposed bow-tie slot antenna combined with the FSS is carried out in section IV. Section V contains the comparison of simulation and experimental results and the insertion of an air gap between the FSS and the slot is outlined in section VI. Finally the main conclusions are drawn in section VII.

\section{RECTANGULAR SLOT ANTENNA}

Microstrip line fed ground plane slot antennas became a subject of great interest to engineers in the field of integrated antennas many years ago [10]-[12]. More recently, some studies moved from increasing the bandwidth and miniaturizing this type of antennas [13], [14] towards increasing the gain provided by combination with FSS structures [14], [15].

The simple rectangular slot is introduced here to be used as a reference for the other slot antennas. The corresponding geometry is shown in Fig. 1. The truncated ground plane and slot dimensions play an important role in the characteristics of the antenna because they can adjust the effects of the electromagnetic coupling between the feed line and the ground and therefore improve the bandwidth [10]-[12].

A low cost FR4 substrate, with relative permittivity 4.4, loss tangent 0.02 and thickness $1.57 \mathrm{~mm}$ is used.

Brazilian Microwave and Optoelectronics Society-SBMO Brazilian Society of Electromagnetism-SBMag received 22 March 2020; for review 26 March 2020; accepted 18 June 2020

(C) 2020 SBMO/SBMag

ISSN 2179-1074 


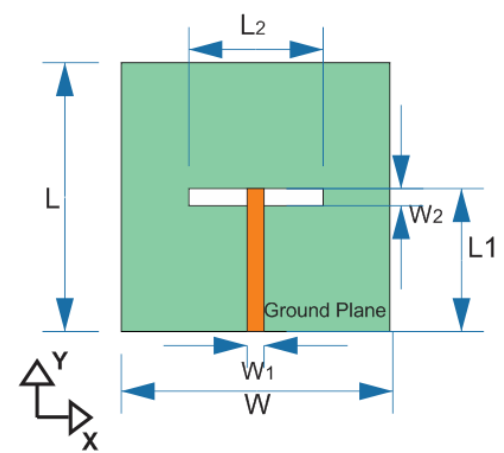

(a)

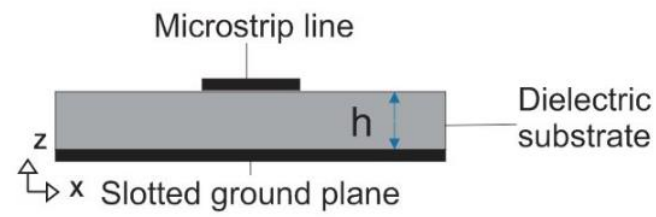

(b)

Fig. 1. Microstrip line fed rectangular slot antenna configuration: (a) top view; (b) side view.

The dimensions of the antenna have been chosen to provide the half-wavelength first resonance frequency at $4.8 \mathrm{GHz}$ and a microstrip feed line with characteristic impedance $50 \Omega$. The transmission line model [16] was used initially to estimate the antenna dimensions and the HFSS software tool was then used to optimize them. The following dimensions have been obtained: $\mathrm{W}=\mathrm{L}=30 \mathrm{~mm}, \mathrm{~W}_{1}=\mathrm{W}_{2}=3 \mathrm{~mm}$, $\mathrm{L}_{1}=\mathrm{L}_{2}=16.5 \mathrm{~mm}$. The input reflection coefficient $\left(\mathrm{S}_{11}\right)$ CST simulation results are shown in Fig. 4 and the far-field radiation pattern cut in the YZ plane and 3D radiation pattern are shown in Fig. 2. A broadside gain of about $3.82 \mathrm{dBi}$ is obtained. A summary of the antenna characteristics is shown in Table I.

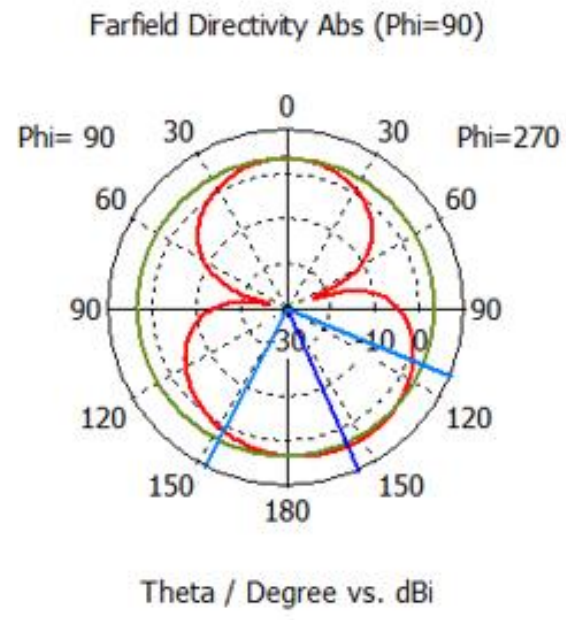

(a)

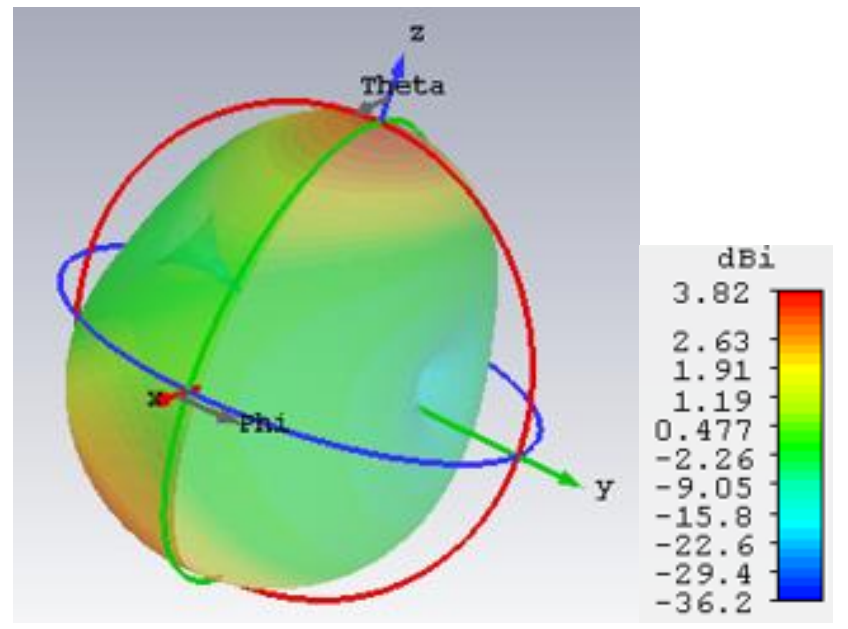

(b)

Fig. 2. Radiation pattern of the rectangular slot antenna at $4.8 \mathrm{GHz}$ : (a) YZ plane cut, and (b) 3D.

\section{BOW-TIE SLOT ANTENNA}

Different shapes of microstrip line fed slots in the ground plane have been proposed mostly to increase impedance bandwidth or provide miniaturization [13], [14], [17]. A very common shape is the bow-tie slot antenna shown in Fig. 3. It keeps the simplicity of the rectangular slot and provides a performance 
enhancement similar to more complex shapes. The geometrical parameters of this slot are the same of the rectangular one, plus $\mathrm{W}_{3}$, the width of the slot at the ends.

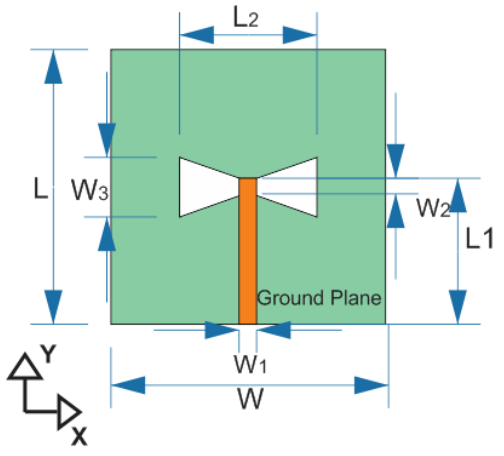

(a)

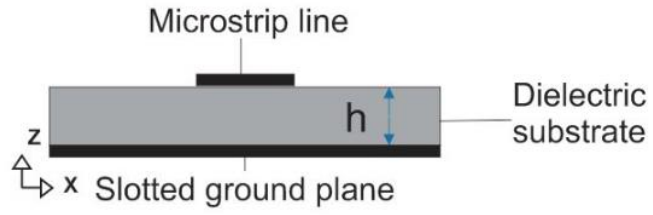

(b)

Fig. 3. Microstrip line fed bow-tie slot antenna configuration: (a) top view; (b) side view.

To evaluate the size reduction and other changes in the antenna performance, the $S_{11}$ and radiation pattern were simulated using HFSS and compared to those of the rectangular slot antenna designed in the previous section. The width of the bow-tie slot at the ends, $\mathrm{W}_{3}$, was varied from $6 \mathrm{~mm}$ to $15 \mathrm{~mm}$ in steps of $3 \mathrm{~mm}$. The other dimensions were the same of the rectangular slot. The $\mathrm{S}_{11}$ HFSS simulation results are shown in Fig. 4. It can be verified that the increase of the slot width leads to a decrease of the resonance frequency which corresponds to a miniaturization effect. As expected, a decrease of the impedance bandwidth is also obtained. Instead of miniaturization, increase of the bandwidth could have been obtained if the resonance frequency were kept constant by changing other antenna parameters, mainly $\mathrm{L}_{2}$.

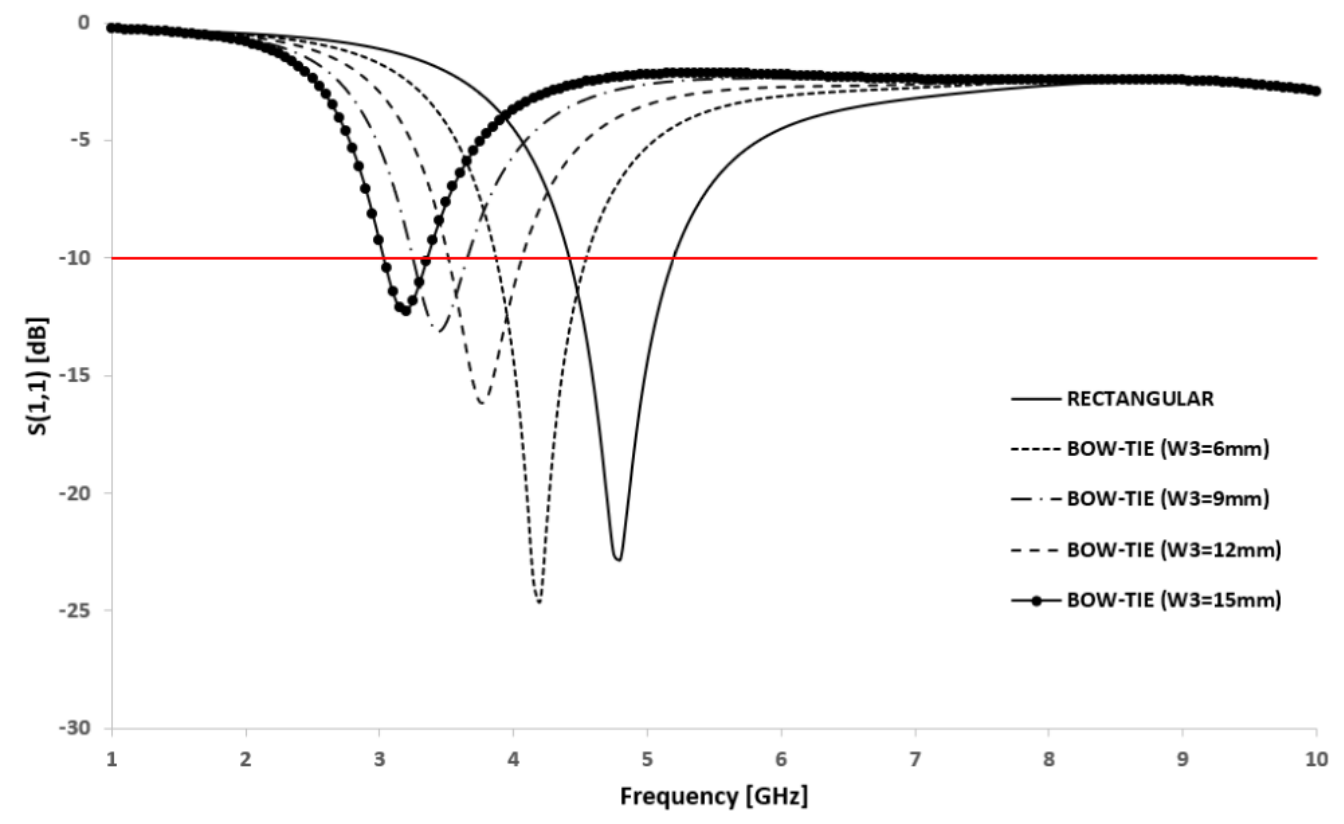

Fig. 4. Simulated $S_{11}$ of rectangular and bow-tie slot antennas. 
Journal of Microwaves, Optoelectronics and Electromagnetic Applications, Vol. 19, No. 3, September 2020 DOI: http://dx.doi.org/10.1590/2179-10742020v19i38

Table I compares the resonance frequency, bandwidth, $\mathrm{S}_{11}$ level at resonance, and size reduction rates of the proposed bow-tie slot antenna. The size reduction values are calculated from the decrease in resonance frequency. It is important to note that the resonance frequency of the proposed bow-tie slot antenna can be 1.6 GHz lower than that of the rectangular one. These results show that the proposed antenna design procedure successfully reduced the size.

TABLE I. COMPARISON OF RECTANGULAR AND BOW-TIE SLOTS HFSS SIMULATED RESULTS

\begin{tabular}{lcccccc}
\hline \hline \multicolumn{1}{c}{ Slot Shape } & $\begin{array}{c}\text { Frequency } \\
(\mathrm{GHz})\end{array}$ & $\begin{array}{c}\mathrm{BW} \\
(\mathrm{GHz})\end{array}$ & $\begin{array}{c}\mathrm{BW} \\
(\%)\end{array}$ & $\begin{array}{c}\mathrm{S}_{11} \\
(\mathrm{~dB})\end{array}$ & $\begin{array}{c}\text { Size } \\
\text { Reduction } \\
(\%)\end{array}$ & $\begin{array}{c}\text { Gain } \\
(\mathrm{dBi})\end{array}$ \\
\hline Rectangular & 4.8 & 0.78 & 16.25 & -22.79 & - & 3.82 \\
Bow-tie $\left(\mathrm{W}_{3}=6 \mathrm{~mm}\right)$ & 4.2 & 0.65 & 15.48 & -24.61 & 12.50 & 3.66 \\
Bow-tie $\left(\mathrm{W}_{3}=9 \mathrm{~mm}\right)$ & 3.8 & 0.55 & 14.47 & -16.00 & 20.83 & 3.50 \\
Bow-tie $\left(\mathrm{W}_{3}=12 \mathrm{~mm}\right)$ & 3.4 & 0.40 & 11.76 & -13.11 & 29.17 & 3.44 \\
Bow-tie $\left(\mathrm{W}_{3}=15 \mathrm{~mm}\right)$ & 3.2 & 0.32 & 10.00 & -12.26 & 33.33 & 3.44 \\
\hline \hline
\end{tabular}

Figs. 5 and 6 present a 2D and the 3D radiation patterns, and the current distribution at $4.2 \mathrm{GHz}$ for the antenna featured in Fig. $3\left(\mathrm{~W}_{3}=6 \mathrm{~mm}\right)$. A gain of $3.66 \mathrm{dBi}$ is observed.

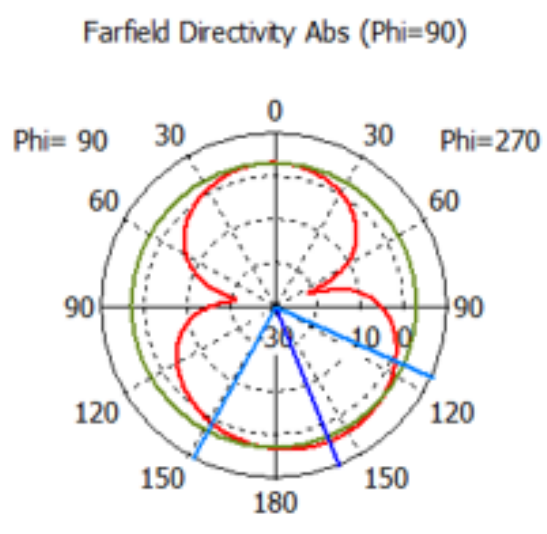

Theta / Degree vs. dBi

(a)

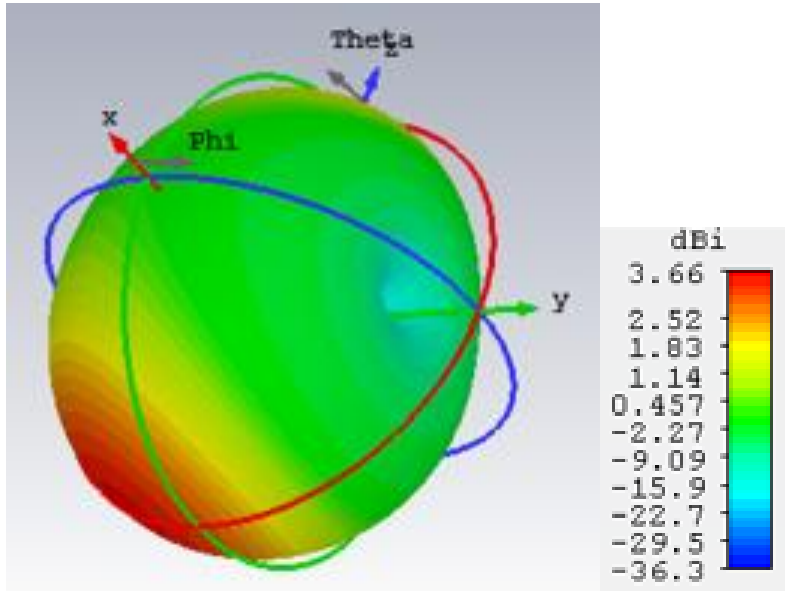

(b)

Fig.5. Radiation pattern of the bow-tie slot antenna at $4.2 \mathrm{GHz}\left(\mathrm{W}_{3}=6 \mathrm{~mm}\right)$ : (a) YZ plane cut, and (b) 3D. 


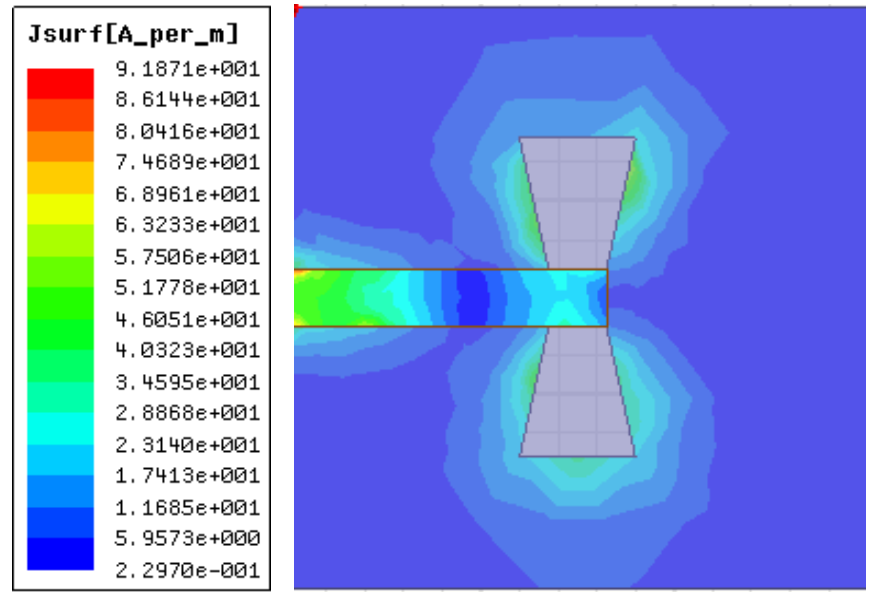

Fig. 6. Current distribution on microstrip line and ground plane at $4.2 \mathrm{GHz}\left(\mathrm{W}_{3}=6 \mathrm{~mm}\right)$.

\section{BOW-TIE SLOT ANTENNA WITH FSS}

Many different techniques have been proposed to improve the parameters of antennas used in specific applications. The FSS is one of them, and has been widely used in modern antenna designs owing to its useful properties [14]-[16]. Periodic configurations such as a series of periodically perforated screens or conducting strips that are either printed on dielectric substrates or free-standing, exhibit FSS characteristics. There are numerous applications of FSSs, including optical and quasi-optical devices, radomes, and dichroic surfaces for antenna reflectors [14]-[16].

The FSS surface can be used with different purposes, such as minimize the negative effects of the surface waves. However, the presence of the FSS near the radiator changes its resonance frequency, which can be controlled in the design mostly by adjusting the dimensions of the element [17], [18].

The FSS structure shown in Fig. 7 is used to optimize the bandwidth and gain of the bow-tie slot antenna (Fig. 3). The methodology used to calculate the slot dimensions and spacing between them is determined through a simulation in HFSS using the Finite-Difference Time-Domain (FDTD) method [19]. As the FSS structure acts as a filter that only allows certain frequencies to be transmitted, the optimal dimensions to obtain the envisaged goal can be found from the observation of the reflection coefficient diagram.

The FSS structure used in the design consists of a matrix of five rows and five columns of square slots, as depicted in Fig. 7. Both the antenna and the FSS have simple structures and are printed on the same substrate. Aiming at the best configuration, the width and length of the FSS square slots (WU=LU) were varied from 0 to $4.5 \mathrm{~mm}$ in steps of $1.5 \mathrm{~mm}$. 


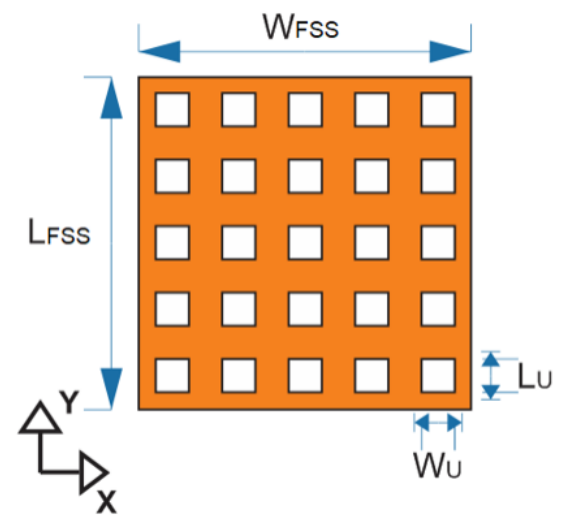

Fig. 7. FSS structure used in the microstrip antenna presented in Fig. $3($ WFSS $=$ LFSS $=30 \mathrm{~mm}$ ).

The FSS is used overlapping the antenna under analysis, as shown in Fig. 8.

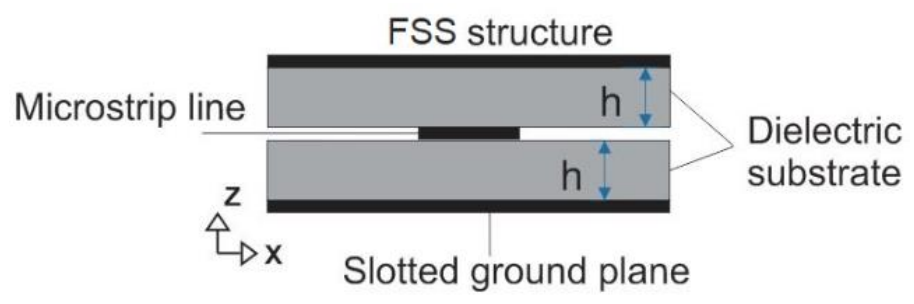

Fig. 8. Profile of the FSS structure used in the microstrip antenna presented in Fig. $3(\mathrm{~h}=1.57 \mathrm{~mm})$.

The proposed slot antenna is fed by a $50-\Omega$ microstrip line to facilitate integration with other circuits and devices.

Initially, we have analyzed the input reflection coefficient of the configurations presented in Fig. 1 and Fig. 3. The corresponding results are presented in Fig. 4. It can be noted that, between 1 and $10 \mathrm{GHz}$, the bow-tie slot antenna without FSS has only one resonance (at $4.2 \mathrm{GHz}$ for $\mathrm{W}_{3}=6 \mathrm{~mm}$ ). However, from the results shown in Fig. 9, for the bow-tie antenna plus FSS, it can be concluded that the use of the FSS provides miniaturization (the first resonance decreased to $2 \mathrm{GHz}$ ) and introduces additional resonances (at about 5.0, 7.2, 7.7, and $8.9 \mathrm{GHz}$ ). This is the best performance obtained and corresponds to $\mathrm{WU}=\mathrm{LU}=3 \mathrm{~mm}$.

The multiband behavior achieved is very important in modern $4 \mathrm{G}$ and $5 \mathrm{G}$ mobile communication systems, where different services use different bands and where large bandwidths associated with high transmission rates are required [20]-[28]. 


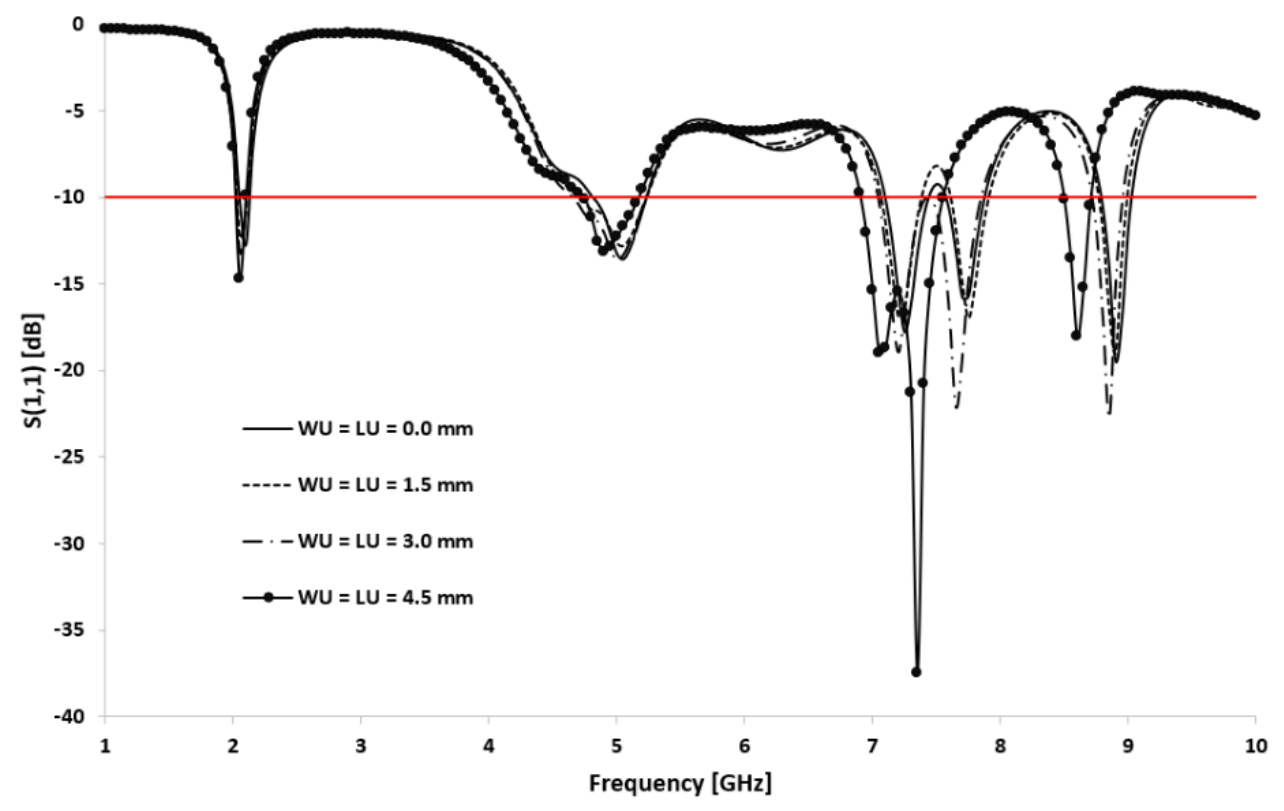

Fig. 9. Input reflection coefficient of the bow-tie slot antenna with FSS.

A 2D and the 3D radiation patterns of the antenna plus FSS and the current distribution on the FSS, for $\mathrm{WU}=\mathrm{LU}=3 \mathrm{~mm}$, are shown in Fig. 10, 11, and 12, respectively. An increase of the gain (from 3.66 to 4.20 $\mathrm{dBi}$ ) is obtained.

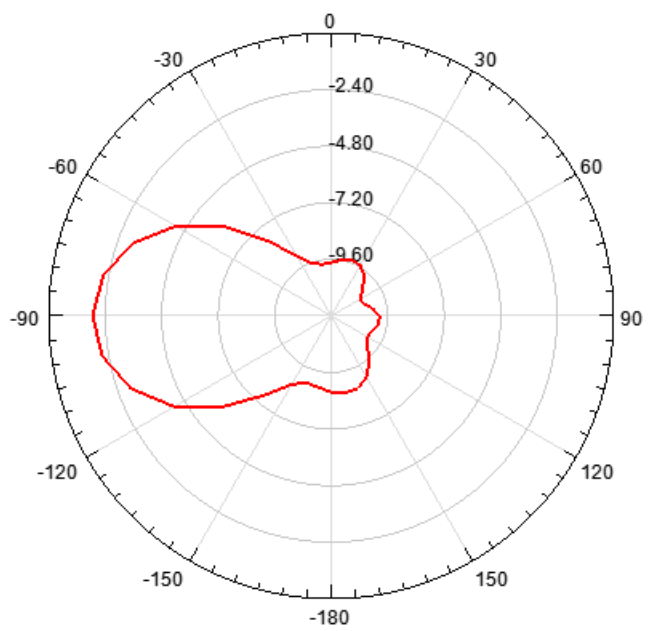

(a)

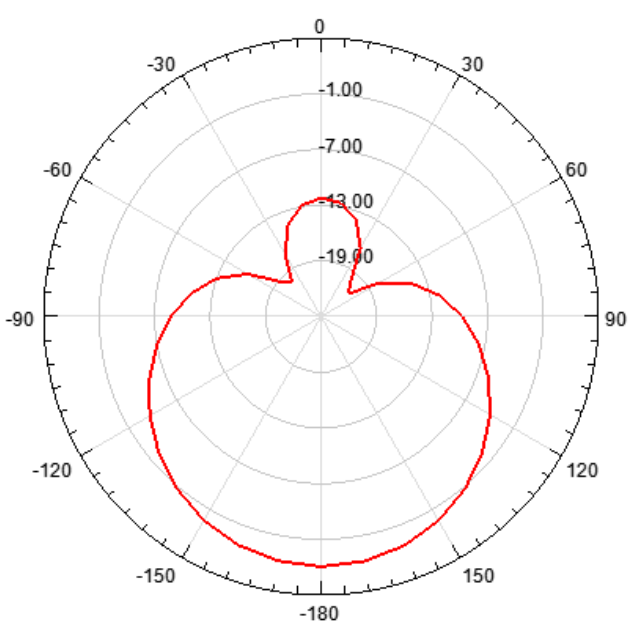

(b)

Fig. 10. 2D radiation pattern of the bow-tie slot antenna plus FSS at $5.0 \mathrm{GHz}$ : (a) XY plane $\left(\varphi, \theta=90^{\circ}\right)$ and (b) XZ plane $\left(\theta, \varphi=0^{\circ}\right)$.

Brazilian Microwave and Optoelectronics Society-SBMO Brazilian Society of Electromagnetism-SBMag received 22 March 2020; for review 26 March 2020; accepted 18 June 2020

(C) 2020 SBMO/SBMag 
Journal of Microwaves, Optoelectronics and Electromagnetic Applications, Vol. 19, No. 3, September 2020 DOI: http://dx.doi.org/10.1590/2179-10742020v19i38

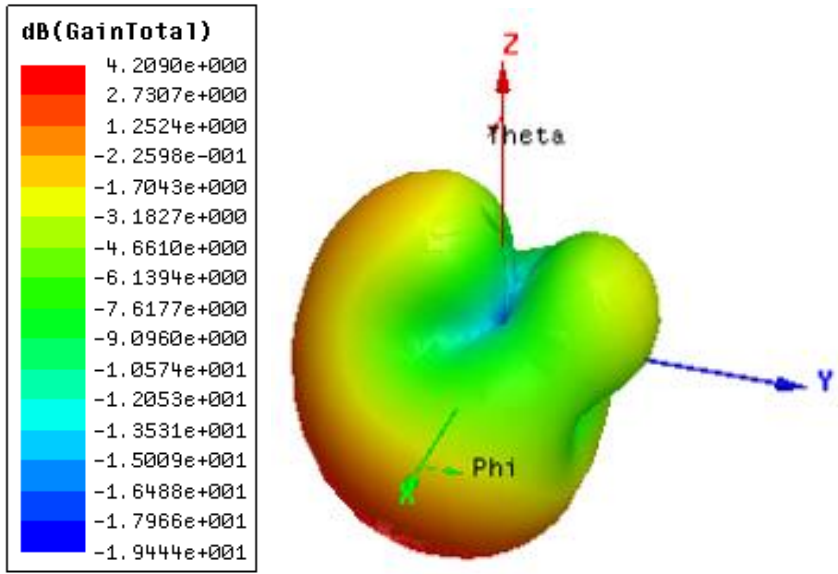

Fig. 11. 3D radiation pattern of the bow-tie slot antenna plus FSS at 5.0 GHz.

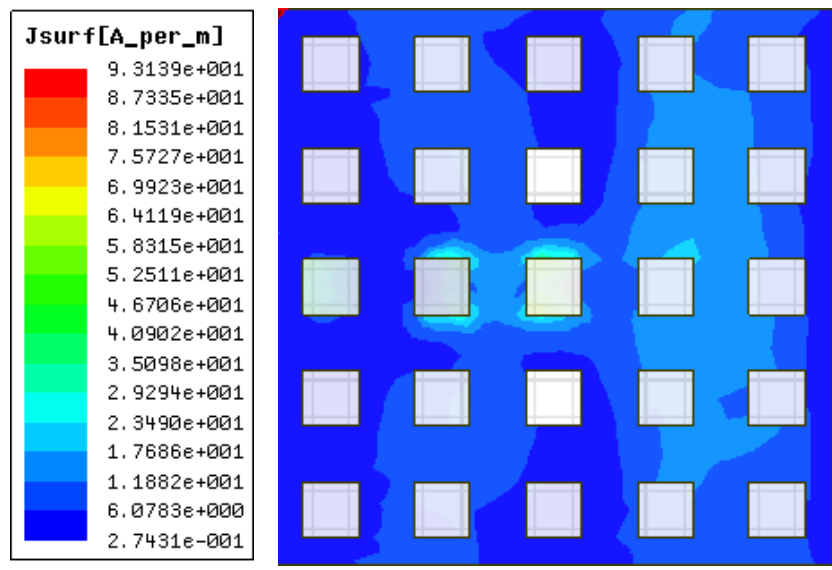

Fig. 12. Current distribution on the FSS structure at 5.0 GHz.

\section{EXPERIMENTS RESULTS}

The proposed antennas are connected to a $50-\Omega$ subminiature version A (SMA) connector for signal transmission, which is considered as a wave port in the vector network analyzer (VNA). This connector is suitable for use up to $18 \mathrm{GHz}$, showing good performance up to approximately $20 \mathrm{GHz}$.

Fig. 13 and 14 show the measurement setup and the bow-tie slot antenna prototype. For this antenna, the result for the input reflection coefficient obtained in the laboratory was compared with that obtained through the HFSS software and is shown in Fig. 15. The agreement between the simulated and measured results is very good for the entire frequency band, which goes up to $10 \mathrm{GHz}$. 
Journal of Microwaves, Optoelectronics and Electromagnetic Applications, Vol. 19, No. 3, September 2020 DOI: http://dx.doi.org/10.1590/2179-10742020v19i38

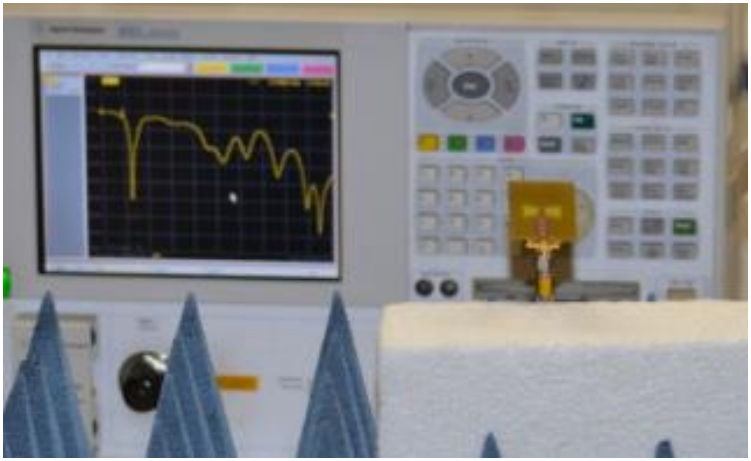

Fig. 13. Measurement of antenna input reflection coefficient with VNA.

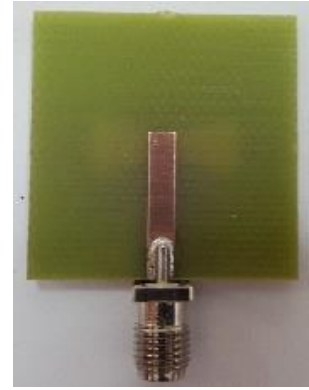

(a)

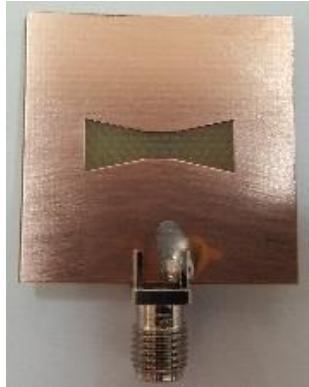

(b)

Fig. 14. Bow-tie slot antenna prototype: (a) microstrip line and (b) ground plane with slot.

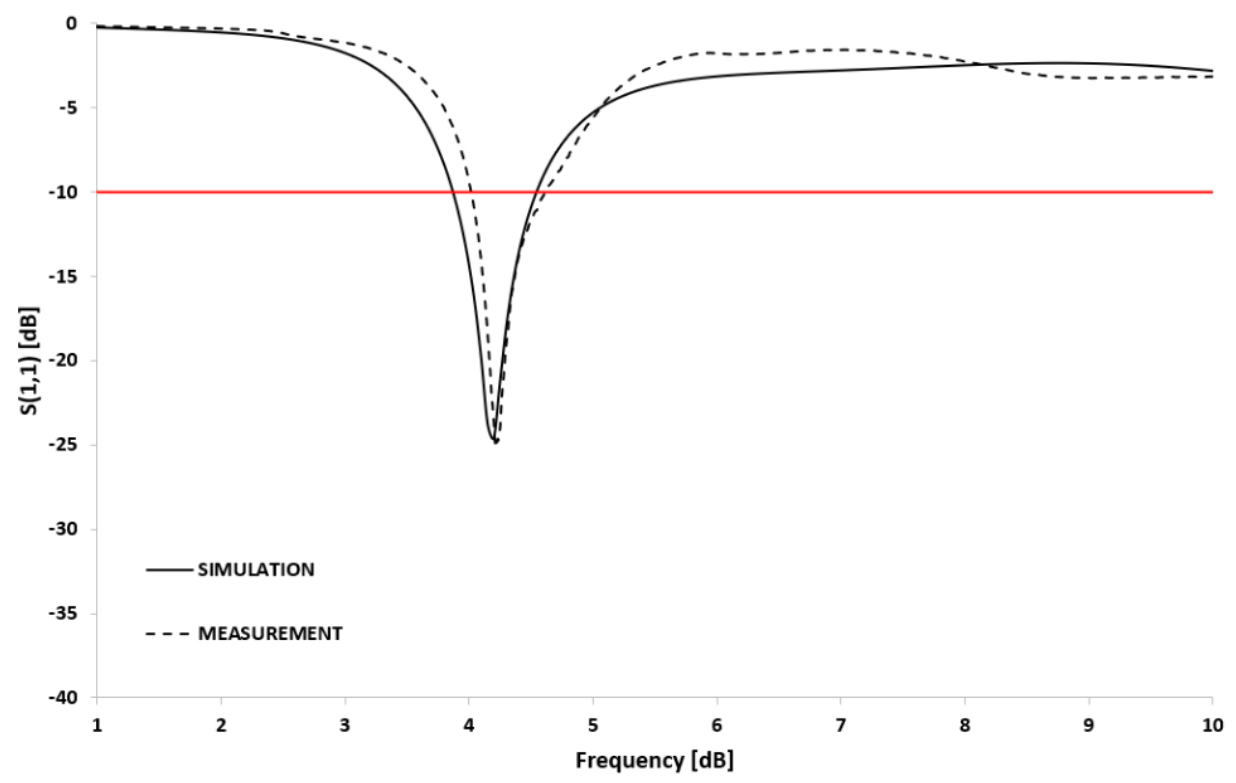

Fig. 15. Input reflection coefficient results of the bow-tie slot antenna.

The measurement of the radiation pattern of the antenna prototype shown in Fig. 14 was carried out in an anechoic chamber wherein the antenna was attached to a Styrofoam (expanded polystyrene) structure possessing a relative electrical permittivity of about 1.05 (Fig. 16). The presence of the structure did not 
Journal of Microwaves, Optoelectronics and Electromagnetic Applications, Vol. 19, No. 3, September 2020 DOI: http://dx.doi.org/10.1590/2179-10742020v19i38

affect the measurements: it only served to mechanically support the antennas. The horn used as a probe in the C band (3.94-5.99 GHz) was a Flann Microwave FMI 12240-15.

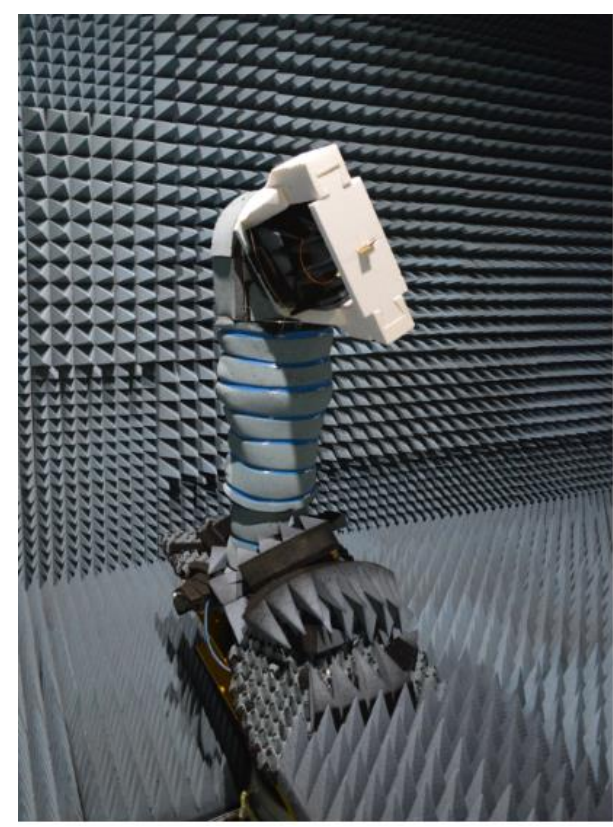

Fig. 16. AUT inside the anechoic chamber.

Fig. 17 shows the prototype of the bow-tie slot antenna with the FSS. For this antenna, the result for the input reflection coefficient obtained in the laboratory was compared with that obtained through the HFSS software and can be seen in Fig. 18. The first three resonances are confirmed experimentally with small detuning but the fourth and fifth one are not observed. This lack of agreement is probably caused by fabrication inaccuracies and misalignment between the antenna and FSS layers.

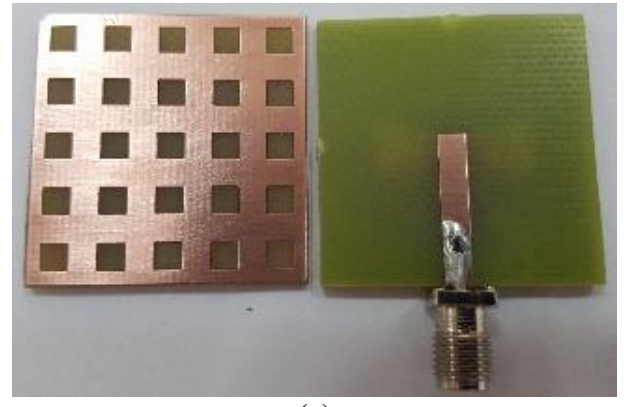

(a)

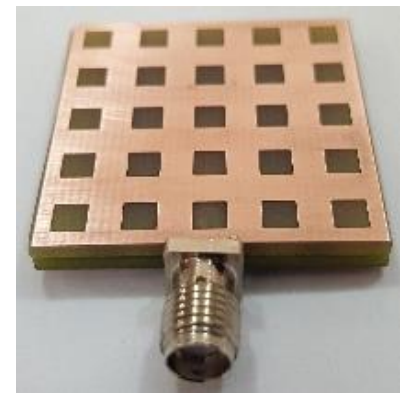

(b)

Fig. 17. Prototype of the slot antenna with the FSS: (a) microstrip line and FSS structure, and (b) antenna with FSS. 


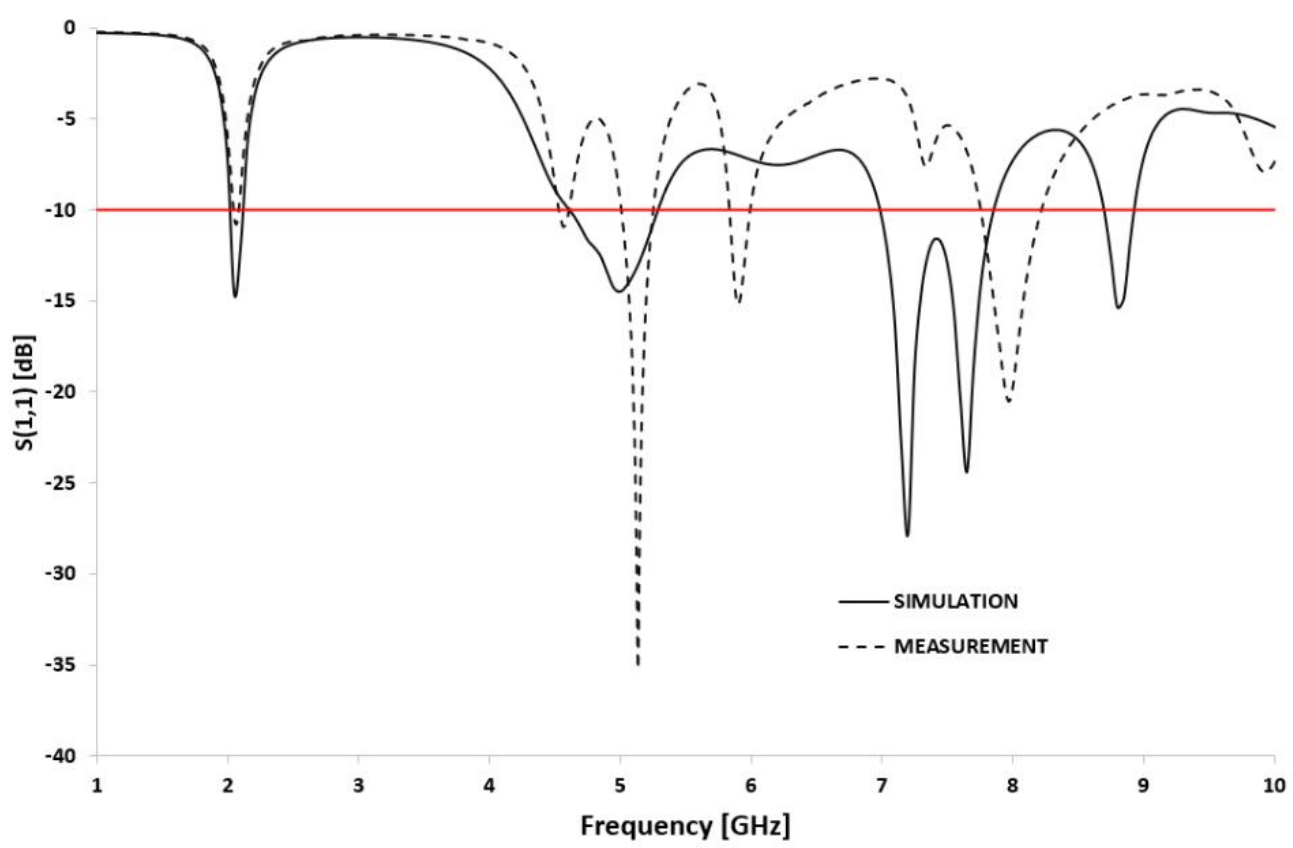

Fig. 18. Input reflection coefficient of the slot antenna with the FSS.

For a better understanding of the simulation and measurement results, Tables II and III summarize the simulated and measured results regarding the slot antenna without FSS and with FSS, respectively.

Some differences in the resonance frequencies between the simulated and measured results can be attributed to inaccuracies in the antenna fabrication process as well as non-ideal conditions during the measurement setup of the analyzed prototypes.

Fig. 19 presents results for the measured radiation pattern of the antennas shown in Fig.14 (at 4.22 GHz) and Fig. 17 (at $5.00 \mathrm{GHz}$ ). Measurements were performed for both E-plane and H-plane and the higher gain values happen at angles between $30^{\circ}$ and $120^{\circ}$, mainly due to the slot in the ground plane. The maximum values found for these antennas are $2.59 \mathrm{dBi}$, in Fig. 19(a), and $5.66 \mathrm{dBi}$, in Fig. 19(b), confirming that the inserted FSS has increased the antenna gain.

TABLE II. SimULATION AND EXPERIMENTAL RESUlTS FOR SLOT ANTENNA WITHOUT FSS

\begin{tabular}{lcc}
\hline \hline & SIMULATED & MEASURED \\
\hline Frequency $(\mathrm{GHz})$ & 4.20 & 4.22 \\
$\mathrm{BW}(\mathrm{GHz})$ & 0.66 & 0.60 \\
$\mathrm{BW}(\%)$ & 15.71 & 14.22 \\
$\mathrm{~S}_{11}(\mathrm{~dB})$ & -23.51 & -25.16 \\
\hline \hline
\end{tabular}


Journal of Microwaves, Optoelectronics and Electromagnetic Applications, Vol. 19, No. 3, September 2020

DOI: http://dx.doi.org/10.1590/2179-10742020v19i38

TABLE III. SimULATION AND EXPERIMENTAL RESULTS FOR SLOT ANTENNA WITH FSS

\begin{tabular}{ccc}
\hline \hline & SIMULATED & MEASURED \\
\hline $1^{\text {st }}$ resonance band & & \\
Frequency (GHz) & 2.06 & 2.15 \\
BW (GHz) & 0.07 & 0.13 \\
BW (\%) & 3.40 & 6.05 \\
$\mathrm{~S}_{11}(\mathrm{~dB})$ & -13.81 & -15.16 \\
$2^{\text {nd }}$ resonance band & & \\
Frequency (GHz) & 4.93 & 5.00 \\
BW (GHz) & 0.53 & 0.26 \\
BW (\%) & 10.75 & 5.20 \\
$\mathrm{~S}_{11}(\mathrm{~dB})$ & -12.63 & -20.10 \\
$3^{r d}$ resonance band & & \\
Frequency (GHz) & 7.44 & 7.34 \\
$\mathrm{BW}(\mathrm{GHz})$ & 0.79 & 0.20 \\
$\mathrm{BW}(\%)$ & 10.62 & 2.72 \\
$\mathrm{~S}_{11}(\mathrm{~dB})$ & -10.17 & -14.65 \\
\hline \hline
\end{tabular}

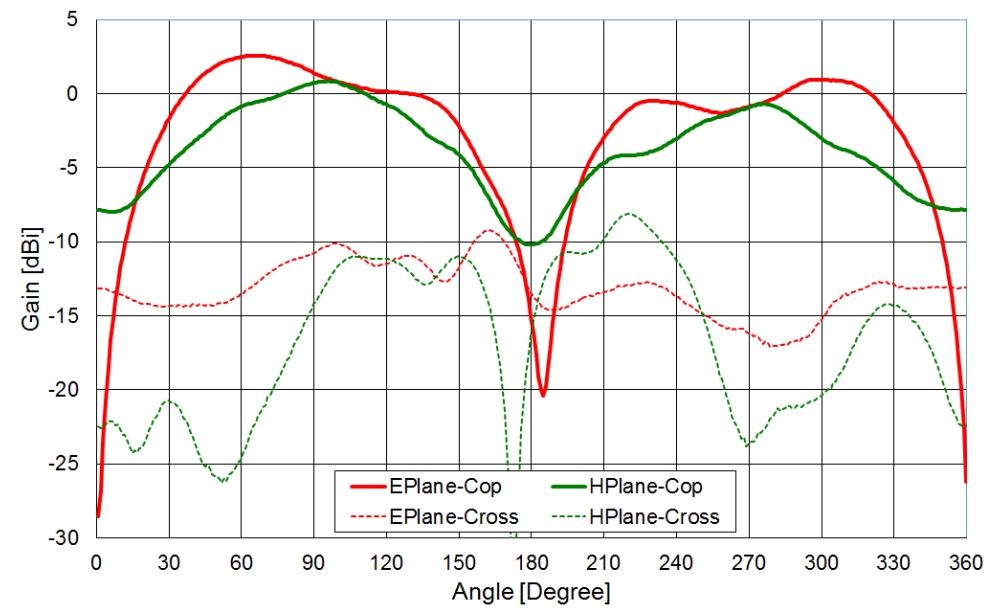

(a)

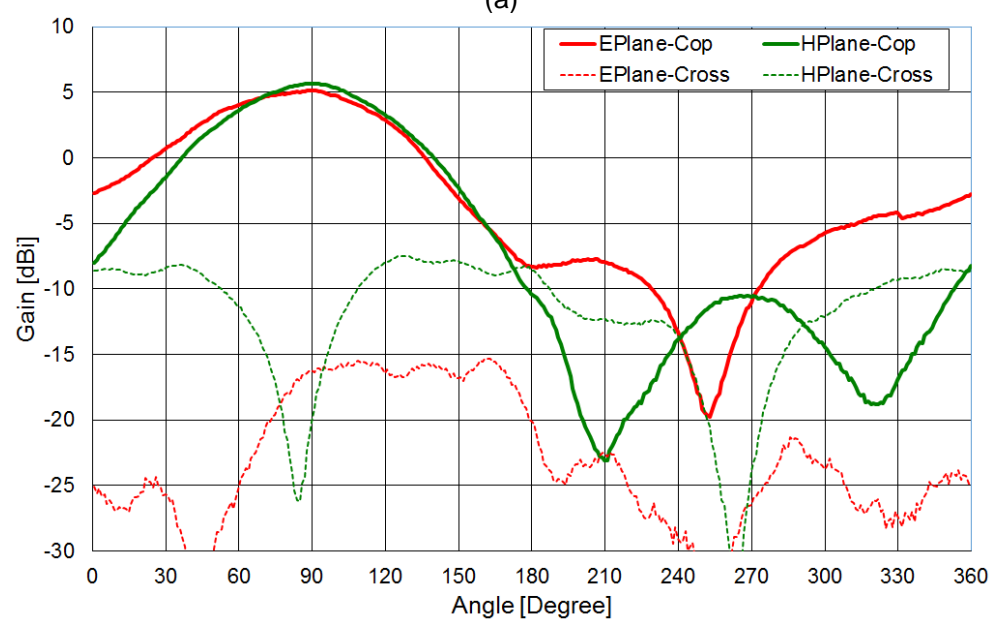

(b)

Fig. 19. E-plane (YZ) and H-plane (XZ) measured radiation pattern results for the antennas shown in: (a) Fig. 14 and (b) Fig. 17.

Brazilian Microwave and Optoelectronics Society-SBMO Brazilian Society of Electromagnetism-SBMag received 22 March 2020; for review 26 March 2020; accepted 18 June 2020 
Journal of Microwaves, Optoelectronics and Electromagnetic Applications, Vol. 19, No. 3, September 2020

DOI: http://dx.doi.org/10.1590/2179-10742020v19i38

\section{AIR GAP INSERTION}

In order to increase the degrees of freedom for the frequency adjustment, air gaps were inserted between the antenna and the FSS structure, as can be seen in Fig. 20.

Fig. 21 presents the results where variations in the resonance frequencies are evident. It is clear that this technique is adequate for providing fine tuning of the antenna.

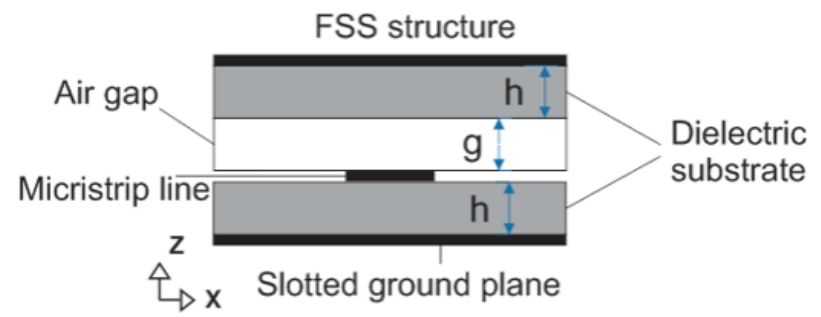

Fig. 20. Bow-tie slot antenna plus FSS structure with air gap.

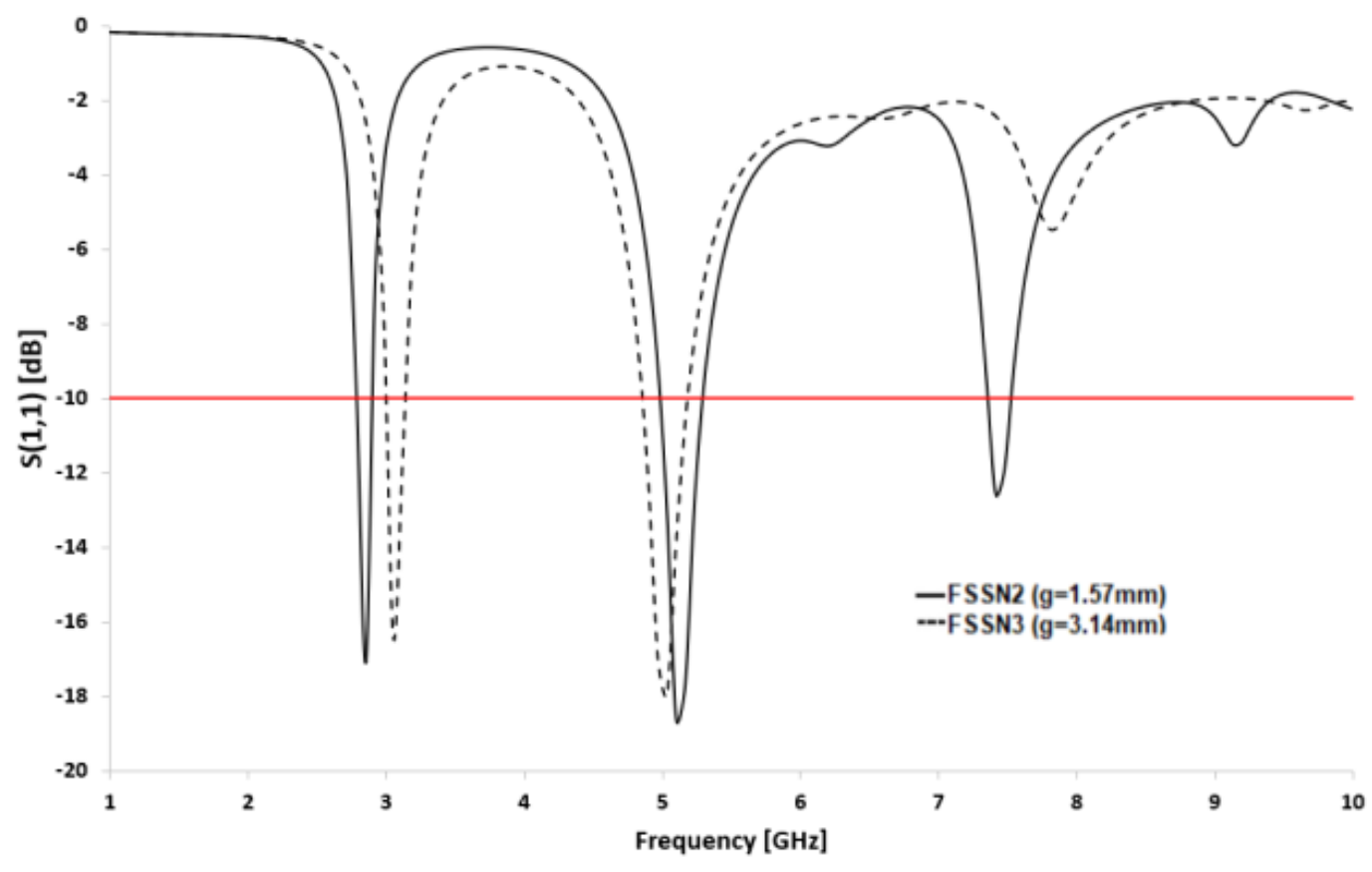

Fig. 21. Input reflection coefficient of the bow-tie slot antenna plus FSS structure with air gap.

Fig. 22, 23, and 24 present the $2 \mathrm{D}$ and 3D radiation patterns and current distribution at $5.09 \mathrm{GHz}$ of the antenna presented in Fig. 20, referring to the FSS structure when $\mathrm{g}=1.57 \mathrm{~mm}$ (FSSN2). A gain close to $4.65 \mathrm{dBi}$ is observed. 
Journal of Microwaves, Optoelectronics and Electromagnetic Applications, Vol. 19, No. 3, September 2020 DOI: http://dx.doi.org/10.1590/2179-10742020v19i38

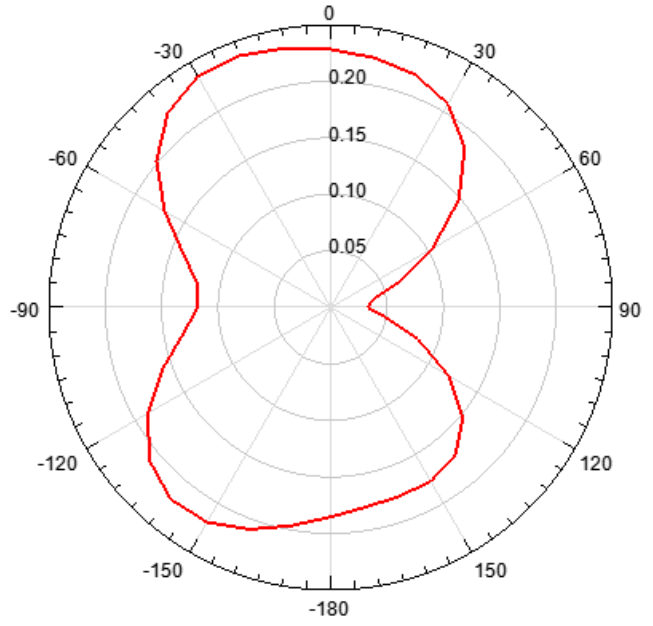

(a)

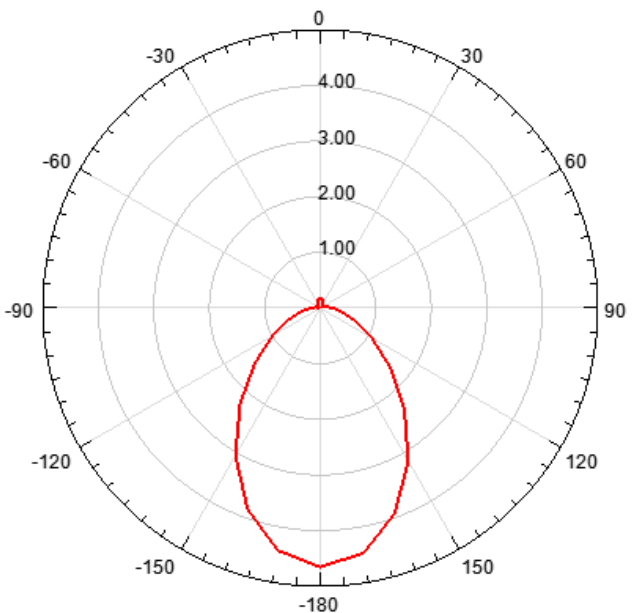

(b)

Fig. 22. Radiation pattern of bow-tie slot antenna with FSSN2 structure at $5.09 \mathrm{GHz}$ : (a) XY plane $\left(\varphi, \theta=90^{\circ}\right)$ and (b) XZ plane $\left(\theta, \varphi=0^{\circ}\right)$.

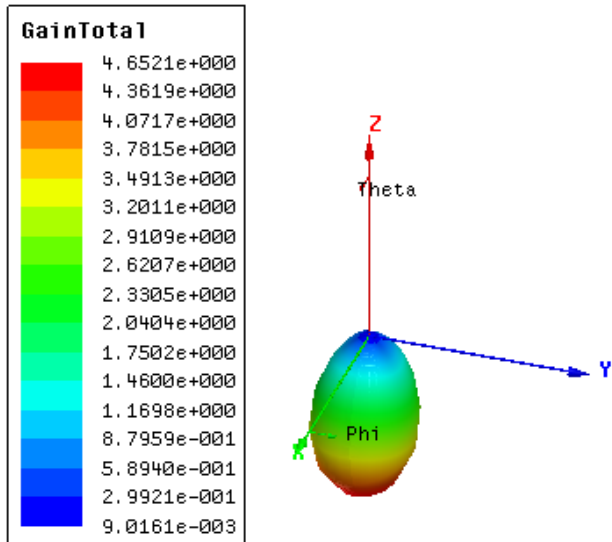

Fig. 23. 3D radiation pattern of the bow-tie slot antenna with FSSN2 structure at $5.09 \mathrm{GHz}$.

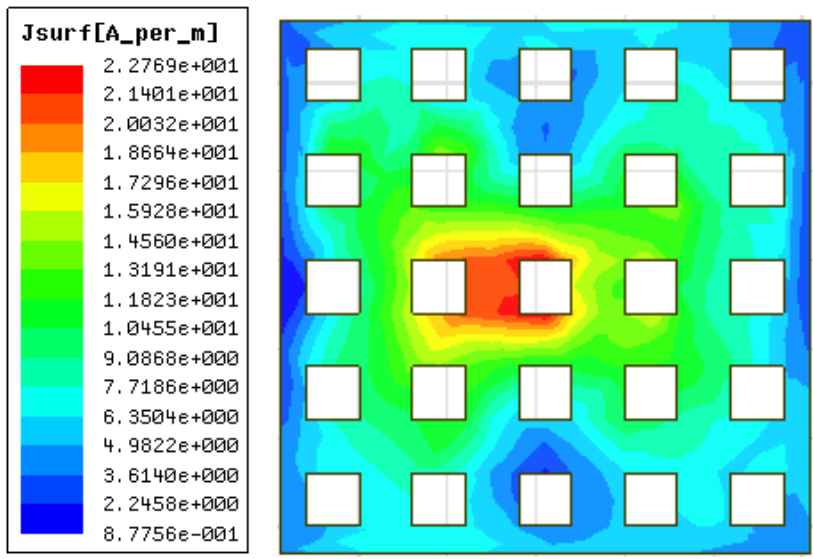

Fig. 24. Current distribution of FSSN2 structure at 5.09 GHz. 
Journal of Microwaves, Optoelectronics and Electromagnetic Applications, Vol. 19, No. 3, September 2020

DOI: http://dx.doi.org/10.1590/2179-10742020v19i38

For the FSS structure presented in Fig. 20 when $\mathrm{g}=3.14 \mathrm{~mm}(\mathrm{FSSN} 3)$, the 2D and 3D radiation patterns, and current distribution at $5.03 \mathrm{GHz}$ are shown in Fig. 25, 26, and 27, respectively.

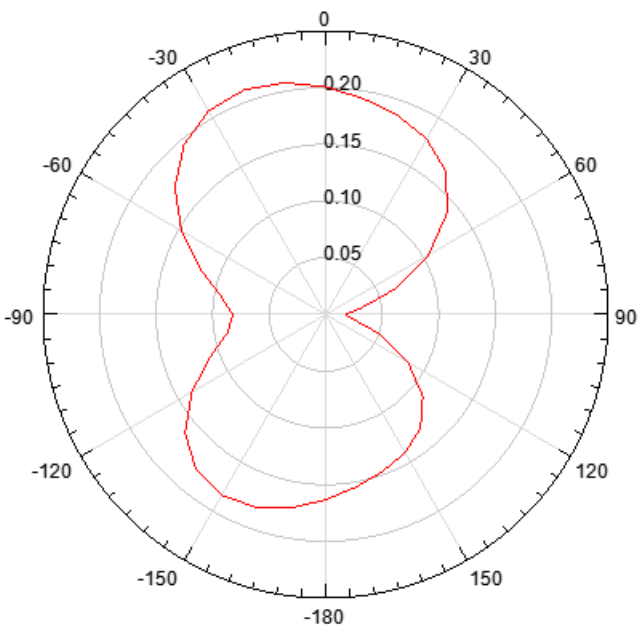

(a)

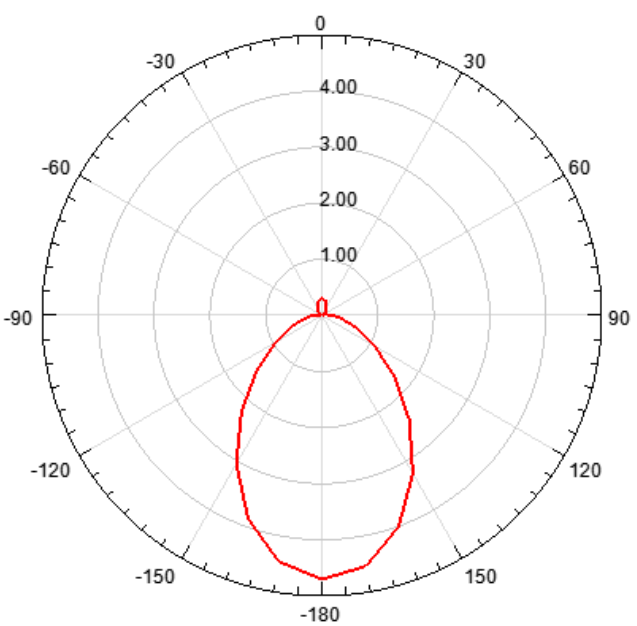

(b)

Fig. 25. Radiation pattern of bow-tie slot antenna with FSSN3 structure at $5.03 \mathrm{GHz}$ : (a) XY plane $\left(\varphi, \theta=90^{\circ}\right)$ and (b) XZ plane $\left(\theta, \varphi=0^{\circ}\right)$

The characteristics of this configuration are remarkably similar to those of the FSSN2 structure, with a small increase in the antenna gain, which is now $4.70 \mathrm{dBi}$.
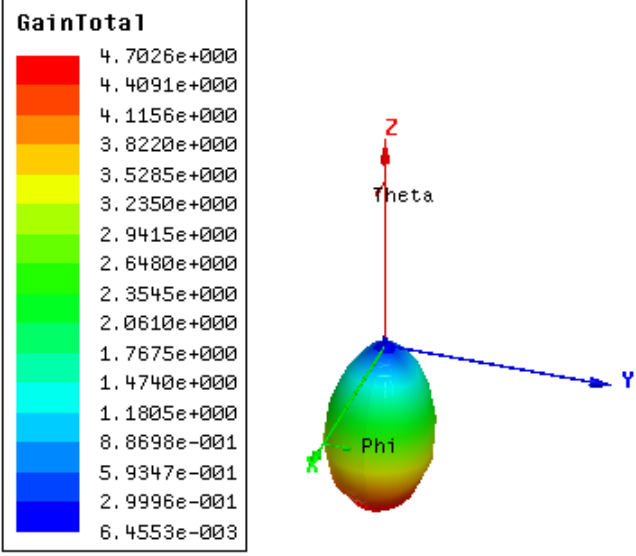

Fig. 26. 3D radiation pattern of the bow-tie slot antenna with FSSN3 structure at $5.03 \mathrm{GHz}$. 


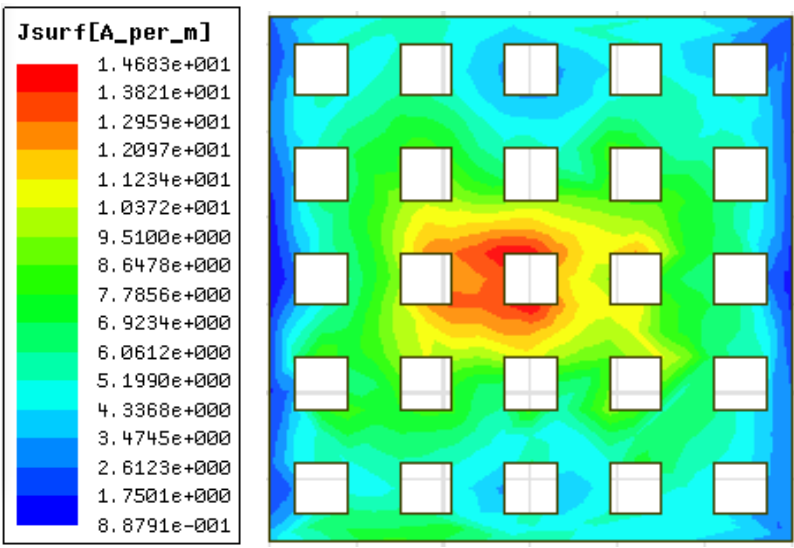

Fig. 27. Current distribution of FSSN3 structure at frequency of $5.03 \mathrm{GHz}$.

\section{CONCLUSION}

The use of a simple FSS structure in a microstrip line fed bow-tie slot antenna is proposed, aiming at miniaturization, multi-frequency behavior, and gain enhancement. Moreover, the use of an air gap between substrates provided fine control of the resonance frequencies. The effects of the FSS structure are illustrated using four application examples: antenna without FSS, antenna with FSS but without air gap, and antennas with FSS and air gaps of two different thicknesses. Simulation results for the input reflection coefficient, current distribution, radiation pattern, and gain are presented and analyzed for the frequency range of 1 to $10 \mathrm{GHz}$. Antenna prototypes were designed, fabricated, and tested. A good agreement is obtained between the numerical simulation and experimental results, which validated the proposed design procedure and new concept for the antenna. Several potential applications can be anticipated with regard to multi-frequency wireless services such as WLAN, WiMAX and 4G and 5G mobile communication systems.

\section{ACKNOWLEDGMENTS}

This work was supported by CNPq under covenant 573939/2008-0 (INCT-CSF), CAPES, Federal University of Rio Grande do Norte (UFRN) and Fundação para a Ciência e a Tecnologia under Grant UIDB/EEA/50008/2020.

\section{REFERENCES}

[1] A. Osseiran, J. F. Monserrat, and P. Matsch, (editors), 5 G mobile and wireless communications technology, Cambridge University Press, 2016.

[2] K. L.-M. Ang and J. K. P. Seng, "Application specific internet of things (ASIoTs): Taxonomy, applications, use case and future directions," IEEE Access, vol. 7, pp. 56777-56590, 2019.

[3] K. R. Jha and S. K. Sharma, "Combination of MIMO antennas for handheld devices," IEEE Antennas Propag. Mag., vol. 60, no. 1, pp. 118-131, Feb. 2018.

[4] T. T. Le, H. H. Tran, and H. C. Park, "Simple-structured dual-slot broadband circularly polarized antenna," IEEE Antennas Wireless Propag. Lett., vol.17, no.3, pp. 476-479, Mar. 2018.

[5] L. Kurra, M. P. Abegaonkar, A. Basu, and S. K. Koul, "FSS properties of a uniplanar EBG and its application in directivity enhancement of a microstrip antenna," IEEE Antennas Wireless Propag. Lett., vol.15, no. 1, pp. 1606-1609, Jan. 2016. 
Journal of Microwaves, Optoelectronics and Electromagnetic Applications, Vol. 19, No. 3, September 2020

DOI: http://dx.doi.org/10.1590/2179-10742020v19i38

[6] A. Pirhadi, H. Bahrami, and J. Nasri, "Wideband high directive aperture coupled microstrip antenna design by using a FSS superstrate layer," IEEE Trans. Antennas Propag., vol. 60, no. 4, pp. 2101-2106, Apr. 2012.

[7] X. Tan, W. Wang, Y. Yu, Y. Liu, and A. A. Kishk, "Enhancing isolation in dual-band meander-line multiple antenna by employing split EBG structure," IEEE Trans. Antennas Propag., vol. 67, no. 4, pp. 2769-2774, Apr. 2019.

[8] D. De and P. K. Sahu, "Design of and endfire microstrip antenna for aircraft collision avoidance system," IEEE Antennas Wireless Propag. Lett., vol.18, no. 5, pp. 996-1000, May 2019.

[9] S. M. A. M. H. Abadi, N. Behdad, "Wideband linear-to-circular polarization converters based on miniaturized-element frequency selective surfaces," IEEE Trans. Antennas Propag., vol. 64, no. 2, pp. 525-534, Feb. 2016.

[10] Y. Yoshimura, “A microstrip line slot antenna," IEEE Trans. Microw. Theory Techn., vol. 20, no. 11, pp. 760-762, Nov. 1972.

[11] B. N. Das and K. K. Joshi, "Impedance of a radiating slot in the ground plane of a microstripline," IEEE Trans. Antennas Propag., vol. 30, no. 5, pp. 922-926, Sep. 1982.

[12] M. Kahrizi, T. K. Sarkar, and Z. A. Maricevic, "Analysis of a wide radiating slot in the ground plane of a microstrip line," IEEE Trans. Microw. Theory Techn., vol. 41, no. 1, pp. 29-37, Jan. 1993.

[13] M. K. T. Al-Nuaimi, "On the miniaturization of microstrip line fed slot antenna using various slots," Int. Conf. Computer Information Appl., Tianjin, China, 2010.

[14] R. Chandel, A. K. Gautam, and B. K. Kanaujia, "A compact rhombus-shaped slot antenna fed by microstrip-line for UWB applications," Int. J. Microw. Wireless Technol., vol. 9, no. 2, pp. 403-409, Mar. 2017.

[15] M. Asaadi, I. Afifi and A.-R. Sebak, "High gain and wideband high dense dielectric patch antenna using FSS superstrate for millimeter-wave applications," IEEE Access, vol. 6, pp. 38243-38250, Jul. 2018.

[16] C. A. Balanis, Antena theory: Analysis and design, $4^{\text {th }}$ edition, John Wiley, 2015.

[17] S. I. Latif, L. Shafai, and S.K. Sharma, "Bandwidth enhancement and size reduction of microstrip slot antennas," IEEE Trans. Antennas Propag., vol. 53, no. 3, pp. 994-1003, Mar. 2005.

[18] C. Chulvanich, J. Nakasuwan, N. Songthanapitak, N. Anantrasirichai and T. Wakabayashi, "Design Narrow Slot Antenna for Dual Frequency," Piers Online, vol.3, no. 7, 2007.

[19] ANSYS HFSS, http://www.ansys.com/Products/Electronics/ANSYS-HFSS.

[20] X. Zhang, Y. Li, W. Wang and W. Shen, "Ultra-wideband 8-port MIMO Antenna Array for 5G Metal-Frame Smartphones," IEEE Access, vol. 7, pp. 72273-72282, May 2019.

[21] B. A. Munk, Frequency Selective Surfaces: Theory and Design. New York, NY, USA: Wiley, 2000.

[22] V. P. Silva Neto, A. G. D’Assunção, and H. Baudrand, “Analysis of finite size nonuniform stable and multiband FSS using a generalization of the WCIP method," IEEE Trans. Electromagn. Compat., vol. 60, no. 6, pp. 1802-1810, Feb. 2018.

[23] S. Narayan and R. Mohan Jha, "Electromagnetic techniques and design strategies for FSS structure applications," IEEE Antennas \& Propagation Magazine, Oct. 2015.

[24] M. E. Newton, S. Mou, K. Ma, N. Yan and F. Meng, "A High Frequency Microstrip Patch Antenna Integrated with FSS Using Substrate Integrated Suspended-Line Technology," International Conference on Microwave and Millimeter Wave Technology (ICMMT), May. 2018.

[25] A. L. P. S. Campos, A. G. D'Assunção, R. H., C. Maniçoba and L. M. Araújo, "Software for project and Analysis of Frequency Selective Surfaces," Journal of Microwaves, Optoelectronics and Electromagnetic Applications, vol. 11, no. 1, pp. 56-67, 2012.

[26] V. Radisic, Y. Qian, R. Coccioli, and T. Itoh, "Novel 2-D photonic bandgap structure for microstrip lines," IEEE Microw. Guided Wave Lett., vol. 8, no. 2, pp. 69-71, Feb. 1998.

[27] P. K. Mishra, V. Sachdeva, D. Sharma, and S. D. Gupta, "Multiband Microstrip Antenna for 4G Mobile Application," Fifth Int. Conf. Commun. Syst. Netw. Technol., Apr. 2015.

[28] A. Agarwal, G. Misra, and K. Agarwal, "The 5th generation mobile wireless networks: Key concepts, network architecture and challenges," American J. Electr. Electron. Eng., vol. 3, no. 2, pp. 22-28, Mar. 2015. 